\title{
Men Urethra Strictures: Findings in Urethroplasties Care at the Andrology and Urology Department of Grand Yoff General Hospital in Dakar
}

\author{
B. Kouame, J. Horace, M. Ndoye, F. Kramo, M. Roua, J. J. Gandonou, S. Yassin, L. Niang, S. M. Gueye \\ Université Félix Houphouët-Boigny, Abidjan, Côte d'Ivoire \\ Email: benjamin_kouam@yahoo.fr
}

How to cite this paper: Kouame, B., Horace, J., Ndoye, M., Kramo, F., Roua, M., Gandonou, J.J., Yassin, S., Niang, L. and Gueye, S.M. (2017) Men Urethra Strictures: Findings in Urethroplasties Care at the Andrology and Urology Department of Grand Yoff General Hospital in Dakar. Open Journal of Urology, 7, 173-185.

https://doi.org/10.4236/oju.2017.710021

Received: January 23, 2017

Accepted: October 28, 2017

Published: October 31, 2017

Copyright (C) 2017 by authors and Scientific Research Publishing Inc. This work is licensed under the Creative Commons Attribution International License (CC BY 4.0).

http://creativecommons.org/licenses/by/4.0/

\begin{abstract}
Objectives: To report the experiment conducted at the HOGGY Urology department in the management of urethral stricture by urethroplasty, and to determine the factors that influence the results. Material and Method: We conducted a descriptive and analytical retrospective study based on the records of patients who underwent urethroplasty in the department, between February 2001 and September 2013. Results: Ninety-one (91) patients were enrolled. Urethroplasties prevalence was $0.83 \%$ of the surgical activity of the service. The mean age of patients was 39.83 years. Dysuria (30.77\%) followed by pelvic trauma $(28.57 \%)$ and urinary retentions $(25.27 \%)$ was the main discovery mode. A periurethral coating was found in 32 patients. The infectious etiology accounted for $44 \%$ of cases. In $63 \%$ of cases, diagnostic was made by retrograde cystography. The penile urethra was the favorite seat of the UR in $70 \%$ of cases. The average length of the urethral stricture (US) was less than $1 \mathrm{~cm}$ in $41.17 \%$ of cases. The US was unique in more than half of the cases (58.33\%). Anastomotic urethroplasty was the best surgical technique with $73.63 \%$ of patients. Postoperative morbidity involved 47 patients and was dominated by urinary infections ( 36 year old). The average duration of follow-up of operated patients was 29 months. After 6 months of follow-up, the best results were obtained with the termino-terminal urethroplasty technique with $62.5 \%$. After a follow-up of 4 years, the success rate was $58.24 \%$. The length of the stenosis and the allocation of gestures on the urethra were the two factors of failure. Conclusion: Stenosis is common in our regions. Treatment results are disappointing. Urethroplasty is the gold standard of surgical treatment and anastomotic urethroplasty gives better results.
\end{abstract}




\section{Keywords}

Urethral Stricture, Urethroplasty, Anastomotic Urethroplasty

\section{Introduction}

Urethral stricture or urethral stenosis is one of the most frequent pathologies and the oldest known in urology.

It is a condition of men and its causes are diverse. In developed countries, the iatrogenic etiology dominates; while in developing countries, notably in Senegal, infection causes predominate [1] [2].

However the therapeutic management always arises fear for reoccurrence. Urethroplasties are now the gold standard of curative treatment. That is why, in this study, we present the experience of the Urology Department at the Grand Yoff General Hospital (HOGGY) in the surgical treatment of urethral strictures by urethroplasty.

The disorders of the low urinary organs lay ahead the clinical symptomatology and endoscopy as well as imaging (Retrograde Cystography and Voiding Cystography) make it easy to diagnose.

\section{Material and Method}

It was a single center, retrospective, descriptive study, which took place from February 2011 to September 2013 in the Andrology Urology Department of the Hospital General de Grand Yoff in Dakar.

This study specific objective was to determine the overall frequency of urethroplasties, to study the etiopathogenic, clinic and therapeutic aspects and to evaluate the urethroplasties results in the short and medium term. The average number of urethral strictures in the department was of 16 patients per year.

The population consisted of 91 hospitalized patients treated with urethroplasty for urethral strictures in the Department during the study period. The population received an agreement notice for the study. The main problem in the research process was the small amount of patients which had uroflowmetry.

All patients treated through meatotomy or meatoplasty, those who had not been treated with urethroplasty but by other techniques (urethral dilation, endoscopic internal urethrotomy) were excluded from the study. A survey sheet prepared for the purpose allowed us to collect epidemiological, clinical and therapeutic data.

\section{Results}

\subsection{Epidemiological Aspects}

The prevalence of urethral stricture in the Department was $0.83 \%$.

Age 
The average age of patients was $39 \pm 6$ year old with extremes of 4 years old and 84 years old. The age group most affected by the disease was aged between 20 - 29 years as shown in Figure 1 below.

\subsection{Diagnostic Aspects}

1) The circumstances of discovery

Dysuria was the main reason for consultation with $30.77 \%$ of cases as shown in Figure 2.

\section{2) Results of the physical examination}

The results of the physical examination are as shown in Table 1.

\section{3) The etiology of urethral stricture}

Infectious etiologies were the primary cause with $44 \%$ as shown in Figure 3.

4) Distribution of patients according to additional tests for diagnostic purposes

In $63 \%$ of cases the diagnosis was obtained by performing the retrograde cystography with voiding sequence as shown in Figure 4.

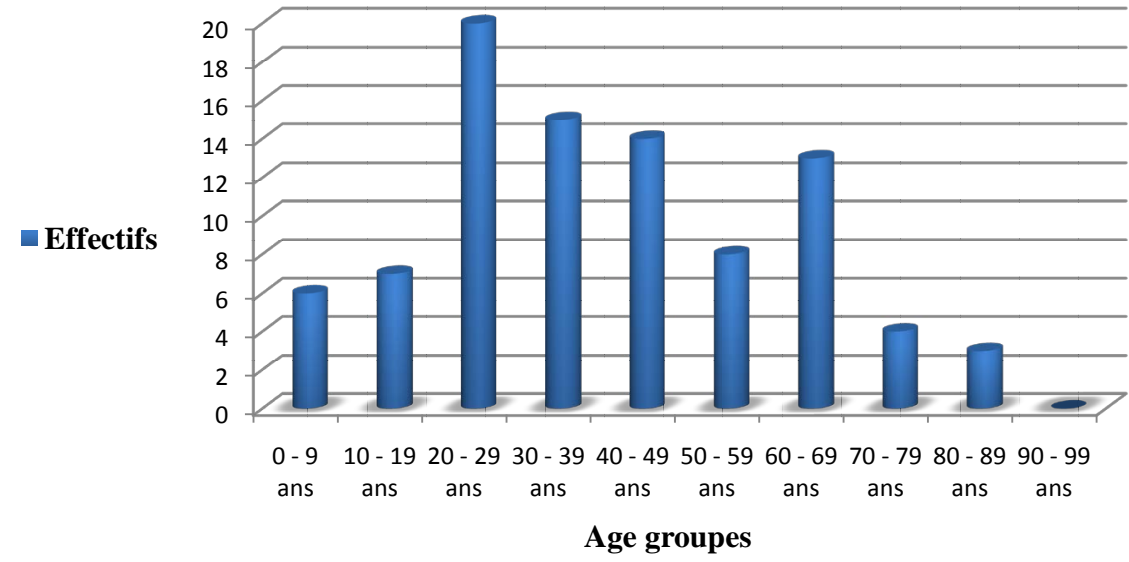

Figure 1. Distribution of patients by age group. Ans = years.



Figure 2. Distribution according to the circumstance of discovery. 
Table 1. Breakdown according to data from physical examination.

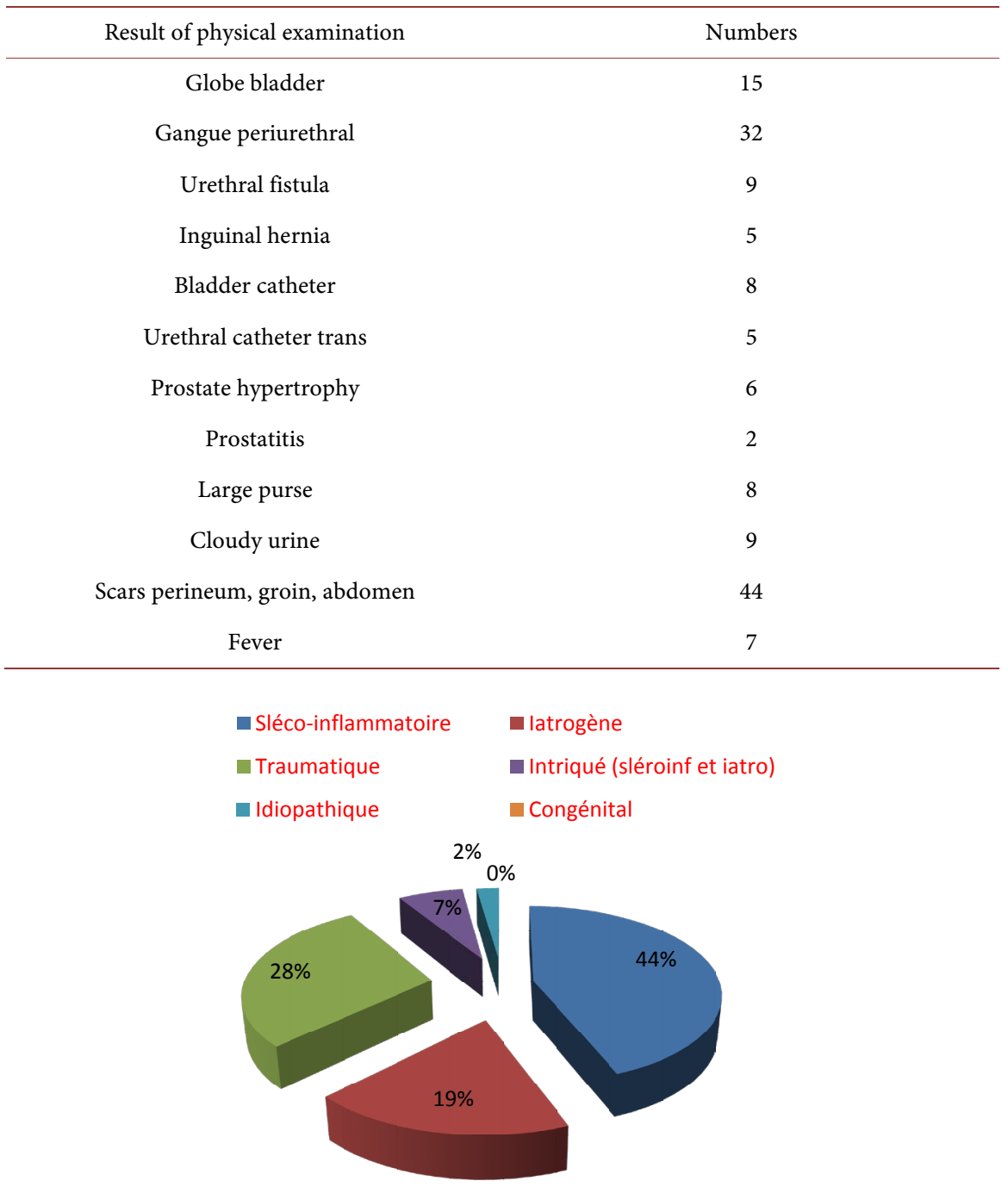

Figure 3. Repartition according to urethral stricture etiology. Sléco-inflammatoire $=$ Sleco-inflammatory; Traumatique $=$ Traumatic; Idiopathique $=$ idiopathic; Latrogène $=$ iatrogenic; Intriqué = Entangled; Congénital = Congenital.

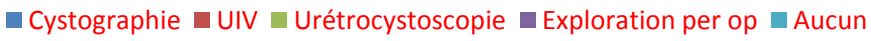

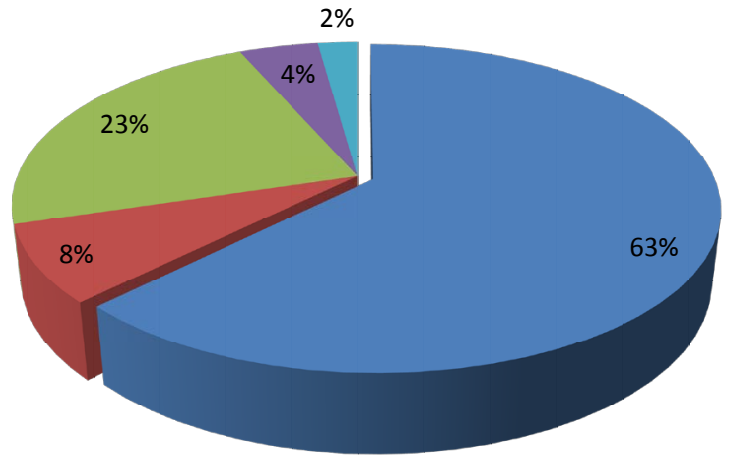

Figure 4. Distribution according to the additional tests that allowed the diagnosis. Cystographie = cystography; Urétrocystoscopie = urethra cystoscopy; Aucun = none. 


\section{5) Site and number of stenosis}

In $70 \%$ of cases, the site was anterior; posterior and antero-posterior in $15 \%$ each. The average length of urethral stricture was between $[0-1] \mathrm{cm}$ in $41.1 \%$, it was unique in $58 \%$, staged in $26.38 \%$ and extended in $15.2 \%$ cases.

\section{6) Pre-surgery complications of urethral stricture}

Table 2 below shows the different pre-surgical complications of urethral stricture.

\subsection{Therapeutic Aspects}

1) The time before receiving care

The average time before care was 2 months 8 days \pm 12 days with extremes of 1 day and 2 years as shown in Table 3.

\section{2) Urethroplasty technique}

Anastomotic Urethroplasty was performed for $73.6 \%$ of patients, followed by the Quartey procedure in $16.48 \%$ of cases as shown in Figure 5.

\section{3) Accidents and Incidents}

We count 04 incidents of rectal injuries during the procedures.

\section{4) Post surgery data}

The duration of hospitalization was $14.83 \pm 8$ days with extremes of 1 and 30 days.

Table 4 below shows the distribution by hospital stay.

a) Period of carrying a urinary tract catheter

Table 2. Distribution according to pre-surgical complications.

\begin{tabular}{cc}
\hline Complications & Numbers \\
\hline Peri-urethral cellulitis & 13 \\
Pyelonephritis & 1 \\
Kidney failure & 17 \\
Prostatitis & 2 \\
Orchiepididymitis & 3 \\
Total & 36 \\
\hline
\end{tabular}

Table 3. Distribution of patients according to the time before care.

\begin{tabular}{ccc}
\hline Period (days) & Numbers(n) & Percentage (\%) \\
\hline $0-1$ & 3 & 3.30 \\
$2-6$ & 6 & 6.59 \\
$7-14$ & 10 & 10.99 \\
$21-30$ & 15 & 16.48 \\
$60-90$ & 39 & 42.86 \\
$120-180$ & 10 & 10.99 \\
$210-330$ & 3 & 3.30 \\
\hline
\end{tabular}




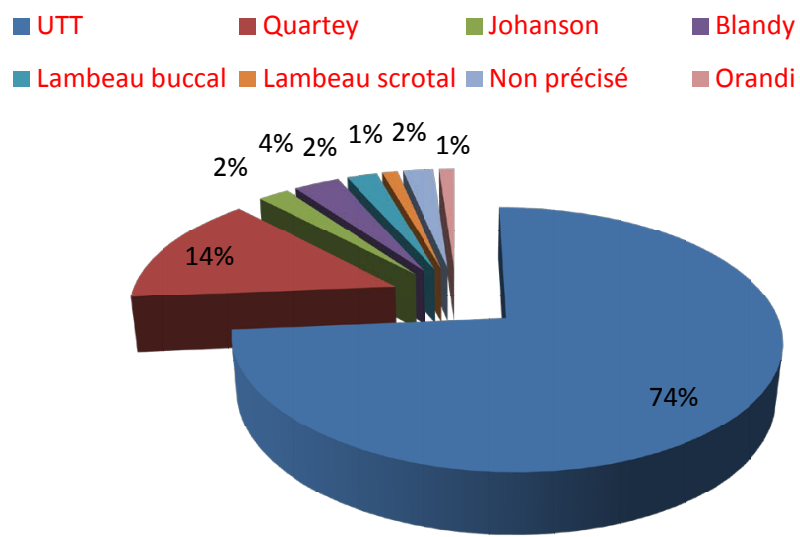

Figure 5. Distribution according to the urethroplasty technique used. Lambeau buccal = buccalflap; Lambeau scrotal $=$ Scrotal flap; Non precise $=$ unspecified.

Table 4. Distribution by hospital stay.

\begin{tabular}{ccc}
\hline Number of days & N & Percentage (\%) \\
\hline$[1-3]$ & 6 & 6.6 \\
{$[4-6]$} & 26 & 28.6 \\
{$[7-10]$} & 17 & 18.7 \\
{$[11-15]$} & 10 & 11.0 \\
$>$ à 16 & 5 & 5.5 \\
Unspecified & 25 & 27.5 \\
Total & 91 & 100 \\
\hline
\end{tabular}

The average time of the urethral catheter wearing was $11.55 \pm 11$ days with extremes of 7 and 65 days, as shown in Table 5.

b) Post surgery morbidity

It is reported in Table 6.

5) Post-surgery urinary infections

After urethroplasty, urinary infection concerned $17.5 \%$ of patients. The main bacteria found in urine culture were:

a) Escherichia coli (33\%);

b) Staphylococcus aureus (29\%).

Figure 6 shows Breakdown by germ found in the urine culture after urethroplasty.

6) Post-surgery results

a) Post-surgery care modes

The average duration of post-surgery follow-up was 29 months with extremes of 3 and 48 months. After 24 months, most patients were unreachable for follow up.

A urinary flow measurement control was performed in 18 patients, as shown in the Table 7.

b) Short, medium and long-term results 
Table 5. Distribution of patients according to time of urethral probe wearing.

\begin{tabular}{ccc}
\hline Catheter wearing duration (weeks) & $N$ & Percentage (\%) \\
\hline$[1-3]$ & 19 & 20.88 \\
{$[3-6]$} & 27 & 29.67 \\
{$[6-9]$} & 6 & 6.59 \\
$>$ ou $=9$ & 4 & 4.40 \\
Non précisé & 35 & 38.46 \\
Total & 91 & 100 \\
\hline
\end{tabular}

Table 6. Distribution according to post-surgery morbidities.

\begin{tabular}{lc}
\hline Morbidity & Number \\
\hline Urinary tract infection & 16 \\
Inflamed bursa & 4 \\
Urinary incontinence & 2 \\
Shortening rod & 2 \\
ED & 7 \\
Anejaculation & 2 \\
Pulmonary embolism & 1 \\
Urethro-cutaneous fistulas & 16 \\
Parietal suppurations & 18 \\
TOTAL & 68 \\
\hline
\end{tabular}

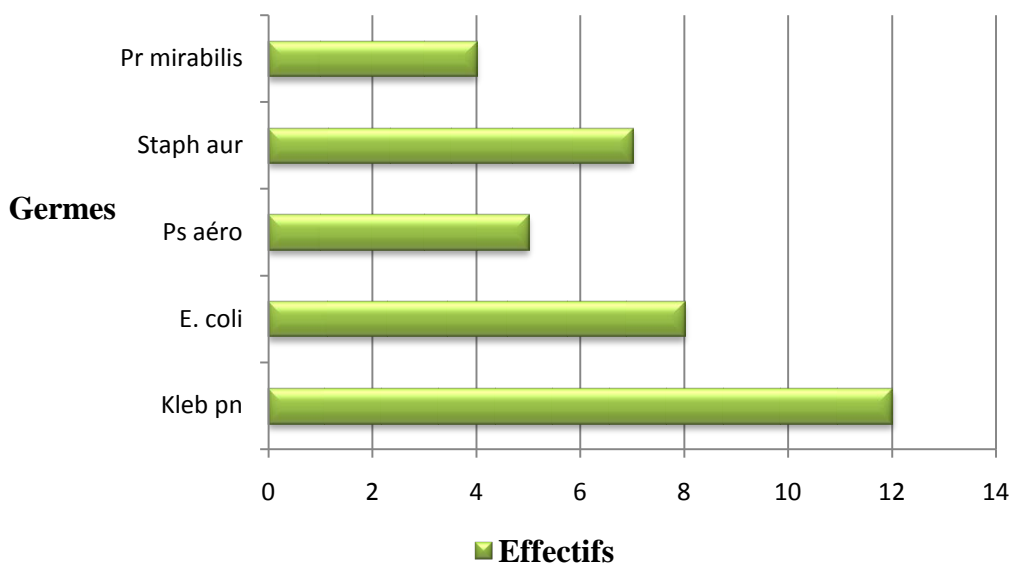

Figure 6. Breakdown by germ found in the urine culture after urethroplasty. Germs = germs; Effectifs = numbers.

After 06 months of follow-up, $62.5 \%$ of good results were reported in the end to end urethroplasty technique (10/16), 25\% with the Quartey technique and $12.5 \%$ with other techniques, as shown in Figure 7.

7) Result according to urethroplasty technic

The end to end urethroplasty gave better results than the Quartey technic and other technics combined as shown in Figure 8. 
Table 7. Distribution of patients who had urinary flow measurement in the post-surgical care.

\begin{tabular}{ccc}
\hline Urine flow & N & Percentages (\%) \\
\hline $25 \mathrm{ml} / \mathrm{s}$ & 4 & 22.22 \\
{$[15-25] \mathrm{ml} / \mathrm{s}$} & 3 & 16.67 \\
{$[10-15] \mathrm{ml} / \mathrm{s}$} & 3 & 16.67 \\
$<10 \mathrm{ml} / \mathrm{s}$ & 8 & 44.44 \\
Total & 18 & 100 \\
\hline
\end{tabular}

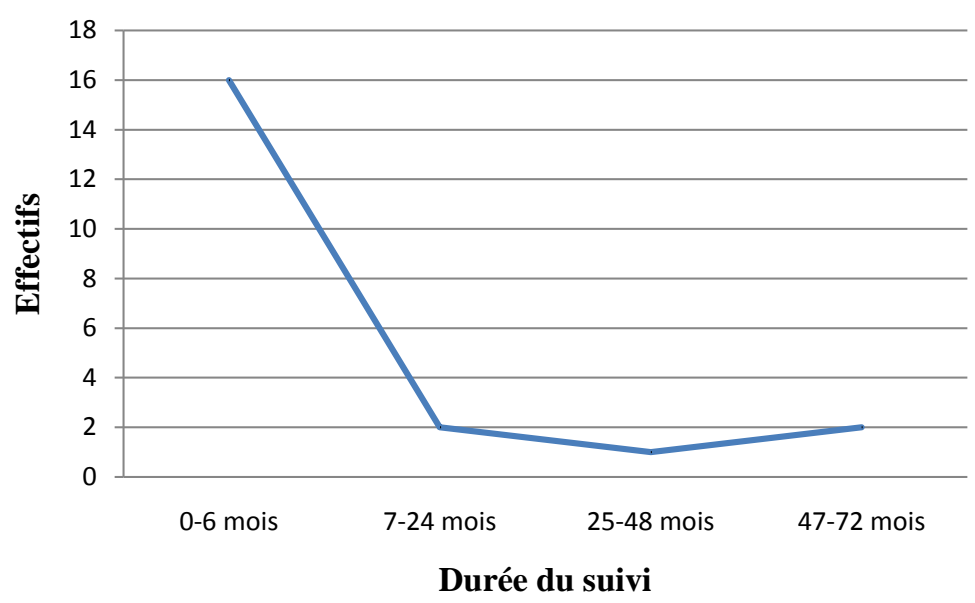

Figure 7. Actuarial curve of the good results based on the follow up. Durée de suivi = follow-up period; Mois = months; Effectifs = numbers.

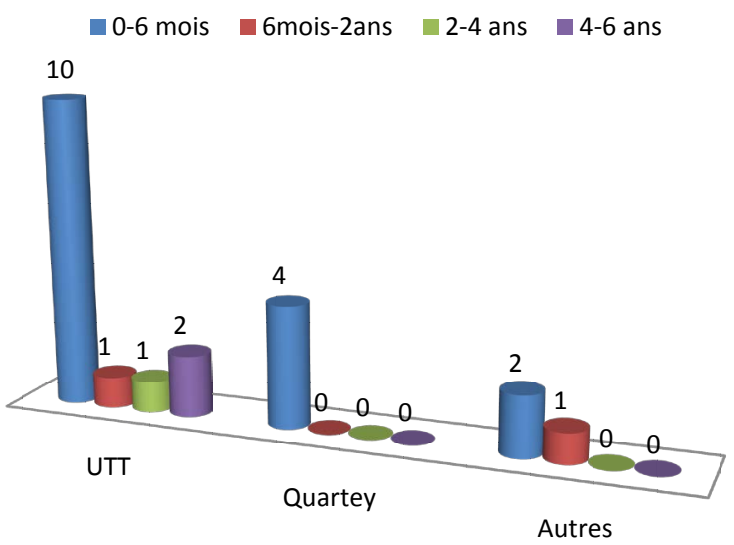

Figure 8. Distribution of good results according to the urethroplasty technique. Autres = others.

After 4 years, the success rate was $58.24 \%$ and the failure rate $41.76 \%$; however, 32 patients were unreachable for follow up.

\section{Discussion}

\subsection{Epidemiological Aspects}

\section{1) Prevalence}


Urethroplasties represent $0.82 \%$ of the surgical activity in the Department of Urology at Grand Yoff General Hospital. These results are comparable with those found in medical literature. In developed countries, the prevalence is estimated at $0.9 \%[3]$.

On the other hand, in Africa, urethral stricture prevalence is high, mainly in Benin and Mali, were Hounasso and Ouattara found respectively $11.3 \%$ and $7.1 \%$ [4] [5].

This constatation is linked to an increase of urethral trauma and iatrogenic stenosis cases. In other results, inflammatory sclerosus strictures rate is less important $1.6 \%$ for Barbagli and al [6].

\section{2) Age}

Regarding age, urethral stricture was observed in all age groups, but particularly in the period between 20 to 29 years old. The age of our patients ranged from 04 to 84 years old with an average age of 39 years old. Our results are almost identical to those observed by Eziyiin Nigeria where the age ranged from 02 to 75 years old with an average of 44.2 years old [7].

In the study of MRINAL [8], the patient's age was between 17 and 80 years old with an average of 40 years.

This is a condition in young patients as reported in similar studies. In 2011, Fall and al. reported an average age of 43.7 years in Dakar [9]. In Mali, Ouattara and $\mathrm{Al}$. had observed an age group between 20 and 39 years [5].

The increase in transportation and increasing urbanization may explain this trend. This view is shared by Nwofor who reported that in Nigeria the traumatic cause (51.5\%) had supplanted the infectious cause [10].

Conversely a higher age was noted in 1999 in Ivory Coast (between 60-80 years old) [11].

\subsection{Diagnostic Aspects}

\section{1) Discovery circumstances}

The main circumstances of discovery in our study were dysuria $(30.77 \%)$ followed by pelvic trauma (28.5\%) and urinary retentions $(25.27 \%)$.

Dje K. and al. in 1999 had reported 55\% of dysuria and 38\% of urinary retention [11], as Fall and Al. in 2011 [2]. However in 2014, that is to say, three year later, the same author reported $62.7 \%$ for urinary retention and $17.3 \%$ for dysuria [12]. This is explained by an increase in pelvic trauma cases. Urinary retention is the main symptom of post- traumatic causes with $53.85 \%$ and Diallo studies [13] made the same observation. This symptom tends increasingly to dominate other symptoms [7] [12].

\section{2) Characteristics of urethral stricture}

The anterior segment of the urethra was the favorite site of stenosis with $70 \%$. Bulbar portion was the most affected (52.73\%); this finding is almost unanimously agreed upon in the world [14].

Infectious causes accounted for $53.93 \%$ of anterior stenosis locations as in the 
study of Eziyi [7].

The low socioeconomic status and poor hygienic conditions, recognized as predisposing factors for sexually transmitted diseases; stricture proceeds from an inflammation originating from infection of bulbar urethral glands developed in the spongy body. These glands are particularly dense in the immediate retro meatus area and in the bulbar urethra. This explains the prevalence of lesions at the bulbar urethra and the distal portion of the penile urethra. So we understand the anterior location of most of the stenotic lesions in our regions where infectious causes predominate.

Stenosis were less than or equal to $1 \mathrm{~cm}$ in $45.59 \%$ of cases. Diakité and Fall had made the same observation [2]. However, a predominance of longer stenosis is described by several authors [6].

In $58.33 \%$ of cases, urethral stricture was unique, stepped in $26.38 \%$ and extended in $15.27 \%$ of the population studied; which is consistent with the medical literature [1] [4].

The infectious etiology (44\%) predominated in our study. This view is shared by all African authors [4]. The traumatic etiology with $28 \%$ of cases followed the infectious cause. Fall and Al. in 2014 had made the same observation [2].

In the studies conducted in North Africa, Europe and Asia, traumatic causes predominated [15] [16] [17].

\subsection{Therapeutic Aspects}

\section{1) Support time}

The average delay before care was 2 months and 8 days with extremes from 1 day to 2 years. This period is important as explained by OOSTERLINCK who recommended a 03 months delay to operate a urethra after urological gesture; if not, the correction would be on an insufficient length [18] [19].

Of all surgical techniques, end to end anastomosis resection was that used as first line with 73.63\% followed by the QUARTEY technique (16.48\%) [20].

The end to end urethroplasty is the best technique for short to slightly large strictures [7] [21]. Today, it is established that the recidivism rate for the use of flaps or grafts is almost identical. However, morbidity is higher with the flaps of penile skin [22].

The techniques in two times were exceptional in our study with $2.2 \%$. Their indications are rare [11].

\section{2) Evolution}

In evolutionary terms, the average hospital stay was 14.83 days with extremes of 1 and 30 days. Prolonged hospital stays were related with morbidities, concomitant diseases or pre-surgical and early post-surgical complications.

The average duration of urethral catheter wear after urethroplasty was 11.55 days. According to Oosterlinck and Al. two weeks are sufficient in 95\% of cases and keeping the urethral probe longer seems unnecessary [23].

Elsewhere, the urethral probe device was kept longer (21 days) [12] [23]. The 
urethra never heals through the catheter, but quite the contrary.

The movements of the probe and the infection it generates inevitably through the biofilm that surrounds it will interfere with the epithelialization. The latex also has a direct toxic effect, so it should be avoided. Prolonged catheterization prevents scar retraction. A sutured anastomosis evolves better than a urethra which must heal only around a probe [14].

Postoperative morbidity was observed in $51.65 \%$ of the patients. It consisted primarily of infectious complications, dominated by urinary tract infections (36 cases) and parietal suppuration (18 cases). It is found that with prolonged follow-up, this proportion increases. GRANIERI and $\mathrm{Al}$ made the same observation [24].

Concerning the study, the best results were obtained at 6 months with the technique of end to end urethroplasty (62.5\%). This is confirmed by several authors [9] [25] [26].

The lack of constancy in follow-ups due to non-returning patients made it difficult to give a correct interpretation of results which remain under evaluated. We compared our results with those obtained by other authors, as shown in $\mathrm{Ta}$ ble 8.

The recurrence rate was $36.26 \%$ with 4 years of pullback. Today, it is established that the length of the urethral stricture is a predictive factor for recurrence [14].

The post-surgical follow-up period proves to be an important factor for an assessment of the time to onset of recurrence but there are many controversies. In our study the maximum failure was observed in the interval [6 months - 2 years]. The non-returning patients made it difficult to interpret Figure 7, but showed evidence of stability in results from 2 years. These observations are shared by other authors [27].

\section{Conclusion}

The urethral stricture or urethral stenosis is one of the most frequent and also oldest pathologies in urology. In our developing regions, infection causes predominate. Lower urinary tract disorders are at the front of the clinical symptoms. Despite specific and appropriate treatment, recidivism is always to be feared, making any prognosis risky. Urethroplasties are the gold standard of cure and the end to end urethroplasty technique gives better results. For a better prognostic uroflowmetry was to be conducted automatically for all the patients

Table 8. Comparison of results (success and failures) with the decline of other authors.

\begin{tabular}{cccccc}
\hline Authors & Numbers & Success & Failures & Pullback & Year \\
\hline B. Fall et al. [2] & 75 & $61.3 \%$ & $38.7 \%$ & 4 years & 2014 \\
Y-H. Shau et al. [27] & 39 & $46 \%$ & $54 \%$ & 6.33 years & 2015 \\
Our study & 91 & $58.24 \%$ & $41.76 \%$ & 4 years & 2015 \\
\hline
\end{tabular}


and the long term follow-up should be reinforced. Most of the patients lost sight after two years.

\section{References}

[1] Benjelloun, M., Drissi, M., Makhloufi, M., et al. (2008) Traitement des sténoses de l'urètre par urétrotomie interne endoscopique: résultats anatomiques et fonctionnels d'une série de 244 cas. [Treatment of Urethral Strictures by Endoscopic Internal Urethrotomy: Anatomical and Functional Results in a Series of 244 Cases.] African Journal of Urology, 14, 114-119. https://doi.org/10.1007/s12301-008-0002-3

[2] Fall, B., Sow, Y., Mansouri, I., et al. (2012) Etiology and Current Clinical Characteristics of Male Urethra Stricture Disease: Experience from a Public Teaching Hospital in Senegal. International Urology and Nephrology, 2, 16-19.

[3] Anger, J.T., Buckley, J.C., Santucci, R.A., et al. (2011) Trends in Stricture Management among Male Madicare Beneficiaries: Under-Use Urethroplasty? Urology, 77, 481-485. https://doi.org/10.1016/j.urology.2010.05.055

[4] Hounnasso, P.P., Tore Sanni, R., Avakoudjo, J.D.G., et al. (2015) Aspects épidémiologiques et diagnostiques du rétrécissement de l'urètre masculin au centre national hospitalier universitaire Hubert Koutoukou Maga de Cotonou. [Epidemiologic and Diagnostic Aspects of Urethral Strictures in Men at the National Hospital University Center Hubert KoutoukouMaga of Cotonou.] Uro'Andro, 1, 162-165.

[5] Ouattara, Z., Tembely, A., Sanogo, Z.Z., et al. (2004) Rétrécissement de l'urètre chez l'homme a l'hôpital du Point G. [Urethral Strictures in Men at the Point G Hospital.] Mali Méd, 19, 3-4.

[6] Barbagli, G., Guazzoni, G., Sansalone, S., et al. (2012) The Role of Dilation and Internal Urethrotomy as a Risk Factor of Failure in Patients Who Undergoing One-Stage Bulbar Oral Graft Urethroplasty. The Journal of Urology, 2, 16-19. https://doi.org/10.1016/j.urology.2010.05.055

[7] Eziyi, A.K., Olajide, A.O., Etonyeaku, A.C., et al. (2013) One-Stage Urethroplasty for Urethral Strictures at the Ladoke Akintola University of Technology Teaching Hospital, Osogbo, South Western Nigeria. World Journal of Surgery, 37, 2529-2533. https://doi.org/10.1007/s00268-013-2176-5

[8] Mrinal, P., Sanjeev, G., Mayank, P., et al. (2013) A Comparative Study of Dorsal Buccal Mucosa Graft Substitution Urethroplasty by Dorsal Urethrotomy Approach versus Ventral Sagittal Urethrotomy Approach. Hindawi Publishing Corporation, London, $5 \mathrm{p}$.

[9] Barbagli, G., Romano, G., De Angelis, M., et al. (2009) Comparative Retrospective Outcome Analysis of 375 Patients Who Underwent One-Stage Repair of Bulbar Urethra Strictures in a Single Referral Center Experience. European Urology Supplements, 8, 302. https://doi.org/10.1007/s00268-013-2176-5

[10] Nwofor, A.M.E. and Ugezu, A.I. (2004) Urethral Stricture Management. Experience at Nnewi, South East Nigeria. African Journal of Urology, 10, 107-111.

[11] Dje, K., Coulibaly, A., Coulibaly, N., et al. (1999) L'urétrotomie interne endoscopique dans le traitement du rétrécissement urétral acquis du noir africain. A propos de 140 cas. [Endoscopic Internal Urethrotomy in the Treatment of Urethral Strictures in Black Africans: About 140 Cases.] Medecine d' Afrique Noire, 46.

[12] Ngandu, T.J., Ntambue, M.M. and Munabe, K.K.P. (2014) Prise en charge des sténoses de l'urètre dans les hôpitaux de la Miba à Mbuji-Mayi, RDC. [Urethral Strictures Care at the Miba and the Mbuji-Mayi, RDC Hospitals.] Congo Sciences, 2. 
[13] Diallo, A.B., Barry, M., Bah, I., et al. (2007) Les ruptures traumatiques de l'urètre postérieur: Analyse de 87 cas au CHU de Conakry. [Traumatic Rupture of the Posterior Uretha: Analysis of 87 Cases at the Conakry UHC.] African Journal of Urology, 13, 214-219.

[14] Tritschler, S., Roosen, A., Fullhase, C. et al. (2013) Urethral Stricture: Etiology, Investigation and Treatments. Deutsches Arzteblatt International, 110, 220-226.

[15] El-Ammari, J., El-Yazami, O., El-Fassi, M., et al. (2011) L'uréthrorraphietermino terminale dans le traitement des rétrécissements de l'urètre bulbaire et membraneux. [End to End Uretrorraphy in the Treatment of Bulbar and Membranous Urethral Strictures.] African Journal of Urology, 17, 66-71. https://doi.org/10.1007/s12301-011-0013-3

[16] Imbeault, A., Bugeja, S., Frost, A., et al. (2011) The Outcome of Retro Bulbar and Membranous Uretroplasty. International Urology and Nephrology, 43, 969-974.

[17] Song, L.-J. (2015) Changing Trends in the Etiology and Management of Male Urethral Stricture Disease.

[18] Oosterlinck, W. (2000) Traitement chirurgical des rétrécissements urétraux. Réflexions personnelles. [Surgical Treatment of Urethral Strictures. Personal Reflexions.] Progrès en Urologie, 10, 611-617.

[19] Oosterlinck, W., Lumen, N. and Van Cauwenberghe, G. (2015) Traitement chirurgical des sténoses de l'urètre: aspects techniques. [Surgical Treatments of Urethral Strictures: Technical Aspects.] Annales D’ Urologie, 41, 173-207. https://doi.org/10.1016/j.anuro.2007.04.005

[20] Fall, B., Sow, Y., Diallo, Y., et al. (2014) Urethroplasty for Male Urethral Strictures: Experience from a National Teaching Hospital in Senegal. Pan AJOUL, 20, 76-81. https://doi.org/10.1016/j.afju.2014.02.003

[21] Tazi, M.F., Ahallal, Y., El Fassi, M.J., et al. (2009) L'uretrorraphietermino-terminale chez l'homme pour sténose de l'urètre (à propos de $10 \mathrm{cas}$ ). [End to End Uretrorraphy in Men for Urethal Strictures. About 10 Cases.] The Journal of Urology, 14, 8-11.

[22] Dubey, D., Vijjan, V., Kapoor, R., et al. (2007) Dorsal Onlaybuccal Mucosa versus Penile Skin Flap Urethroplasty for Anterior Urethral Strictures: Results from a Randomized Prospective Trial. The Journal of Urology, 178, 2466-2469.

https://doi.org/10.1016/j.afju.2014.02.003

[23] Oosterlinck, W., Lumen, N. and Van Cauwenberghe, G. (2007) Traitement chirurgical des sténoses de l'urètre: Aspects techniques. Techniques chirurgicales Urologie Elsevier Masson SAS. [Surgical Treatment of Urethral Strictures: Technical Aspects. Urology Surgical Techniques Elsevier Masson SAS.]

[24] Granieri, M., Webster, G., Lentz, A., et al. (2014) A Critical Analysis of Patient Reported Complaints and Complications after Bulbar Urethroplasty. The Journal of Urology, 191, e124. https://doi.org/10.1016/j.juro.2014.02.496

[25] Culty, T. and Boccon-Gibod, L. (2007) Anastomotic Urethroplasty for Posttraumatic Urethral Stricture: Previous Urethral Manipulation Has a Negative Impact on the Final Outcome. The Journal of Urology, 177, 1374-1377. https://doi.org/10.1016/j.juro.2006.11.092

[26] Raverya, V. and Boccon-Gibod, L. (2007) Les sténoses post-traumatiques de I'urètre: A propos de 105 cas. [Post-Traumatic Rupture of the Urethra: A Series of 105 Cases.] Progrès en Urologie, 17, 83-91. https://doi.org/10.1016/S1166-7087(07)92231-9

[27] Shau, Y.-H., Wu, S.-T., Kao, C.-C., et al. (2015) Management of Complex Urethral Stricture Disease: Algorithm and Experience from a Single Institute. Urological Science, 291. https://doi.org/10.1016/j.urols.2015.06.291 